\title{
Adansonian classification of mycobacteria
}

\author{
By L. F. BOJALIL, J. CERBÓN AND AMANDA TRUJILLO \\ Unidad de Patología, Escuela de Medicina, U.N.A.M. Hospital General, \\ México 7, D. F. México
}

(Received 1 September 1961)

\section{SUMMARY}

The physiological properties of 229 strains of mycobacteria (photochromogens, scotochromogens, non-photochromogens and rapid growers) and others already classified were analysed. According to their metabolic capacities and using the method proposed by Sneath, three branches were established.

Branch $\mathbf{I}$ is formed by micro-organisms with a high metabolic capacity and rapid rate of growth. It includes Mycobacterium smegmatis, $\boldsymbol{M}$. phlei, $M$. peregrinum sp.nov. and many unnamed strains with great disparity in their characteristics, that were placed in a separate branch labelled 'irregular'.

Branch II includes micro-organisms that utilize only a limited number of carbohydrates. Belonging to this branch are Mycobacterium fortuitum, $\boldsymbol{M}$. marinum, $\boldsymbol{M}$. piscium and $\boldsymbol{M}$. thamnopheos. Three new species are described, two of them rapid growers, $\boldsymbol{M}$. acapulcensis sp.nov. and $\boldsymbol{M}$. runyonii sp.nov. and a scotochromogen, $\boldsymbol{M}$. flavescens sp.nov.

Branch III, formed by Mycobacterium kansasii (photochromogen), $\boldsymbol{M}$. avium (non-photochromogen), $\boldsymbol{M}$. marianum (scotochromogen) and $\boldsymbol{M}$. gordonae sp.nov. (scotochromogen). All are slow growing microorganisms.

Neotype strains of old species are proposed and holotypes of the new species are designated. A key for the identification of these species and a taxonomic tree of mycobacteria are described.

\section{INTRODUCTION}

The relationships existing between the different species of mycobacteria have not been adequately established. It is difficult to decide how to distinguish between two related species. This problem arises from the deficiency of many of the earlier descriptions and in other instances, from the difficulty in interpreting the data. Utilizing the Adansonian method, it has been possible to classify in a logical manner the groups belonging to the rapidly growing mycobacteria (Bojalil \& Cerbón, 1961; Cerbón \& Bojalil, 1961). The advantages of using the method proposed by Sneath (1957) for the analysis of the different characters of bacteria have been shown in several previous reports (Sneath \& Cowan, 1958; Hill, 1959).

The present study aims to analyse the physiological properties of the mycobacteria in order to define the existence and value of previously described species, to determine if the preliminary groups described by Runyon (1955) are homogeneously formed and to establish their place among the Mycobacteriaceae. 


\section{METHODS}

In all, 229 strains regarded is Mycobacterium (acid-fast bacilli) were studied. Some of these strains were received with a species name, but they were considered as unclassified to avoid any bias in the interpretation of the results.

They were first tentatively grouped according to their rate of growth and pigment production in the presence and absence of light.

The following divisions were raade: 115 strains were rapid growers (group IV of Runyon). Of these 69 were not -pigmented and 46 were pigmented. 114 strains showed a slow rate of growth: 44 were scotochromogens (group II of Runyon), 45 were non-photochromogens (group III of Runyon) and 25 were photochromogens (group I of Runyon).

They were maintained in Löw enstein-Jensen medium (Wheeler, 1951), checked for viability and purity by microscopic examination and subculture in different media. Single cell cultures of the strains were used to test their physiological properties in triplicate series.

The biochemical methods used were, in general, those described in a previous report (Bojalil \& Cerbón, 1961). The exceptions were as follows: strains that developed better at temperatures of $28^{\circ}$ were tested at this temperature; the urea solution described by Singer \& Cysner (1952) was used in the differentiation of photochromogens and non-photochromogens. The characters used were as follows.

Acid production from carbohydrates: glucose, mannose, fructose, galactose, L-arabinose, xylose, rhamnose, lactose, sucrose, trehalose, melibiose, raffinose, mannitol, sorbitol, $m$-inositol, erythritol and dulcitol.

Utilization of organic acids as carbon sources: benzoate, citrate, tartrate, succinate, pyruvate and propionate.

Temperatures of growth: $28^{\circ}, 3 r^{\circ}, 45^{\circ}$ and $52^{\circ}$.

Survival to $60^{\circ}$ for $4 \mathrm{hr}$.

Rate of growth: all the strains showing visible growth in 48-72 hr. in LöwensteinJensen medium were considered as rapid growers; the presence of visible growth after one or more weeks was considered slow growth.

Pigment production: those strains producing definitely more pigment when grown in the light were considered photochromogens; those uninfluenced by light as scotochromogens and those wi thout pigment as non-photochromogens.

The methods used for the Adansonian classification and the system for quantitative notation were those described by Sneath (1957).

\section{RESULTS}

The results obtained from the different tests were tabulated: a strain $\times$ strain $(i \times i)$ table, was prepared from the similarity indexes obtained, which were expressed in percentages. In sorting the characters of the 229 strains, various distinct patterns were at once discernible. These are shown diagrammatically in Fig. 1, in which each group is represented by only five extities and the intermediate strains are eliminated in order to simplify the interpretation. Subsequently, a taxonomic tree was constructed (Fig. 2), the branches of which may be considered as species. Several species previously characterized remained as groups, or were placed in one of the groups, when subjected to Adansonian analysis. 
The Figs. 1 and 2 show the existence of three major branches of strains which are related at $\mathrm{S}$ levels of $c .60 \%$. One, formed by micro-organisms of high metabolic capacity (branch I), includes two well-defined species, Mycobacterium smegmatis and $M$. phlei; it also includes a large group labelled 'irregular branch' in which each strain could represent a species. The strains numbered 6020 and 128-1 are of particular interest because they are non-pigmented, vigorously fermentative mycobacteria; they have been named $M$. peregrinum sp.nov. All the strains belonging to this branch are rapid growers.

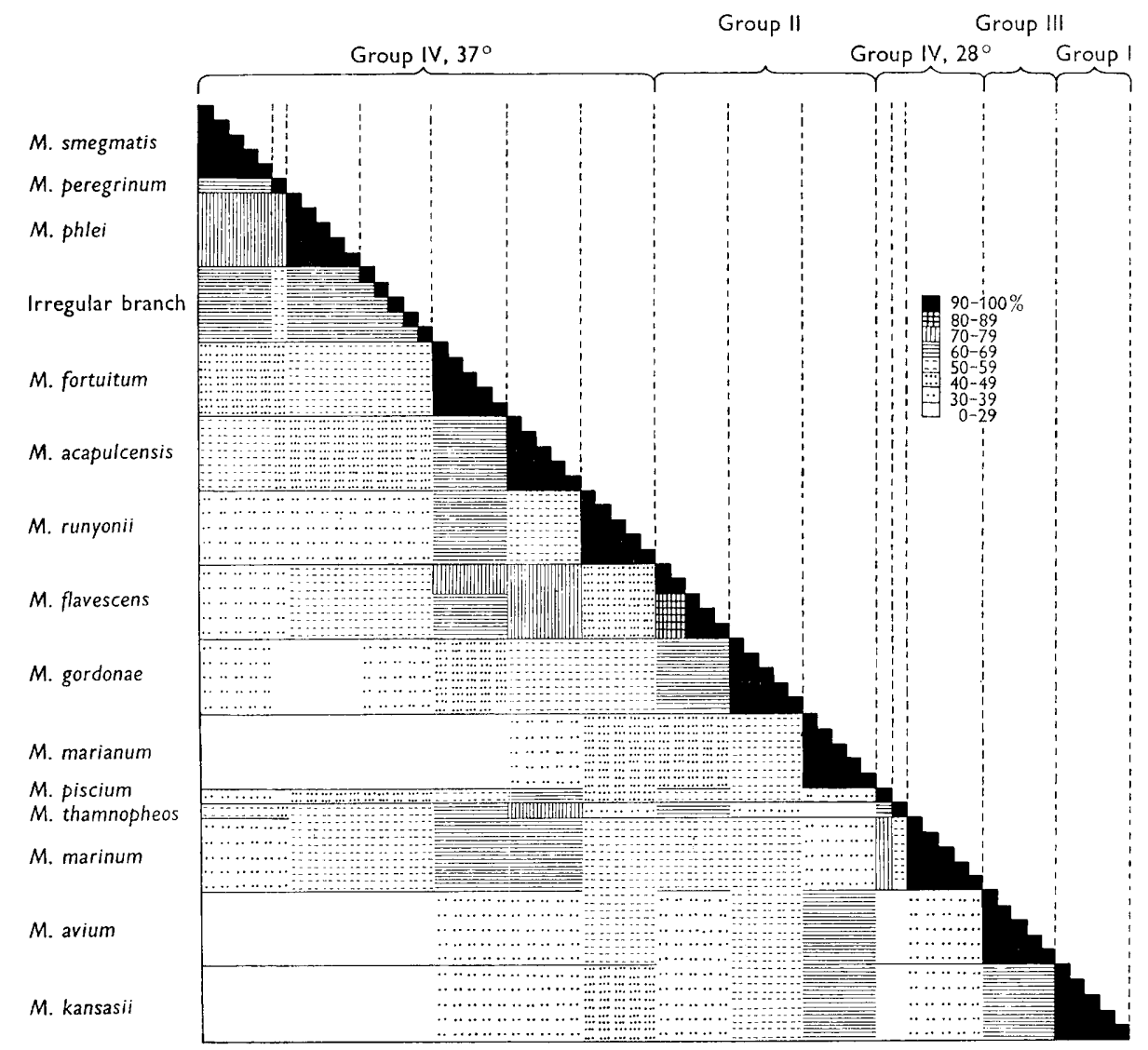

Fig. 1. Diagrammatic representation of the full $\% \mathrm{~S}$ value table.

A second and extensive branch II is constituted principally of rapid growers. Belonging to this branch are Mycobacterium fortuitum, M. piscium, M. marinum and $M$. thamnopheos among the species previously described.

The strains received as Mycobacterium balnei are grouped together with $\boldsymbol{M}$. marinum because they show a high index of similarity. Other groups included in branch II are the following: under the name of $\boldsymbol{M}$. acapulcensis sp.nov. and $\boldsymbol{M}$. runyonii sp.nov. the previously described groups 2 and 3 (Cerbón \& Bojalil, 1961) of the rapidly growing mycobacteria, and a small group of scotochromogens named $\boldsymbol{M}$. flavescens sp.nov. which has a metabolism similar to $M$. fortuitum. 


\section{Table 1}

Laboratory number, name and source.

Strains identified as Mycobacterium smegmatis (Trevisan) Lehmann and Neumann

W-113. M. smegmatis, ATCC 101 Rutgers University, S. A. Waksman

439,11,912, 153, 429. Mycobacterium sp., from different pathological products, Unidad de Patología

Hosp. Gral. (UPHG), México

St-169. M. phlei, Tuberkulose Forschungsinstitut Börstel, R. Bönicke

W-106. M. ranae, National Trudeau Bank, W. Steenken jr.

70. M. lacticola, Escuela Nacional de Agricultura, Chapingo, México

110. M. ranae, ATCC 110, National Trudeau Bank, W. Steenken jr.

607, 599. Mycobacterium sp., Rutgers University, S. A. Waksman

114. $M$. friedmanii, ATCC 114

ATCC 65. Mycobacterium sp., leprae-(i5, ATCC

362. M. butyricum, ATCC 362

281. M. stercoris, A'TCC 281

Strains identified as Mycobacterium peregrinum sp.nov.

6020, 128-1. Mycobacterium sp., fronı a child bronchial aspiration, and from nasal exudate of cattle, UPHG

Strains identified as Mycobacterium phlei, Lehmann and Neumann

NTB, W. M. phlei, National 'Trudeau Bank, W. Steenken jr.

W-1. M. phlei, Rutgers University, S. A. Waksman

1787, 637. Mycobacterium sp., lung biopsy, UPHG

Strains identified as Mycobacterium piscium (Dubard) Bergey et al.

9819. M. piscium, ATCC 9819

Strains identified as Mycobacterium marinum Aronson

7010. M. marinum, NTCC 7010. Neon tetra 1

927. M. marinum, АТCC 927

10011, 10010. M. balnei, NTCC 10011, 10010

Strains identified as Mycobacterium fortuitum, Cruz

11. M. fortuitum, Hektoen Institut for Med. Research (HIMR) Cruz original isolate, ATCC 6841, S. McMillen

6, 6a. M. fortuitum, Medical Research Council Unit, Oxford 6-Wells and Weiss $6 a$-Wells strains NCTC 8573, HIMR, S. McMillen

5, 7. M. fortuitum, 5 leg biopsy Wise; 7 Sputum Schumpert

10. M. fortuitum, M. minettii Penso, HIMR, S. McMillen

14, 15, 16, 17. M. fortuitum, 14, 17, bovine mastitis; 15 soil; 16 NCTC 8697, HIMR, S. McMillen

20, 38, 39, 41. M. fortuitum, 38, halibut strain NCTC 2291; 20, 39, 41 from sputum. HIMR, S. McMillen

156. M. fortuitum, Communicable Disease Center, Atlanta, Georgia, G. Kubica

HI-5836. Mycobacterium sp., UPHG. 13ronchial aspiration

66038. Mycobacterium sp., AFIP, Mayc Clinic, A. G. Karlson

274. Mycobacterium sp., Communicable Disease Center Atlanta, G. Kubica

CAR, CC. Mycobacterium sp., Western Fish Disease Laboratory, Seattle, Washington., Carson Strains, (CAR), and Chambers Cretk strains (CC), J. Ross

SN-413. Mycobacterium sp., Tuberkulose Forschungsinstitut, Börstel. R. Bönicke

1216. Mycobacterium X, University of Jilorida, E. Suter

8, 131, 231, 232, 405, HI-501, HI-503, 400, RD-112, AC-164, AC-242, AC-328, AC-621, AC-624, AC-625, AC-674, AC-681, AC-713, A.C-833, AC-1523, 1919. Mycobacterium sp., from different pathological products 
Table 1 (cont.)

Strains identified as Mycobacterium thamnopheos Aronson

4445. M. thamnopheos, ATCC 4445

Strains identified as Mycobacterium flavescens sp.nov.

D-50, D-25, D-15, 2159, 1078, 787. Mycobacterium sp., from guinea-pigs with tuberculosis arrested by chemotherapy (D-50, D-25 and D-15) and from human biopsies, UPHG

Strains identified as Mycobacterium acapulcensis sp.nov.

343, 103, 102, 465, 358. Mycobacterium sp., from sputum. Acapulco Campaign against tuberculosis, UPHG

Strains identified as Mycobacterium runyonii sp.nov.

380, 518, 481. Mycobacterium sp., Veterans Administration Hosp. Salt Lake City, E. H. Runyon 29. Mycobacterium sp., Hepatic abscess, Cuba, A. Curbelo

AC-561. Mycobacterium sp., Acapulco Campaign against tuberculosis

Strains identified as Mycobacterium gordonae sp.nov.

P-15, 251. Mycobacterium sp., Veterans Administration Hosp., E. H. Runyon RNGO, LLE/RAS, 17. Mycobacterium sp., Colombia, G. Muñoz Rivas

R-41, PTB, D-13, CN-16, 168, CN-21, SIM, 591, SMG, 166, CN-30. Mycobacterium sp., from different pathological materials, UPHG

Strains identified as Mycobacterium marianum Penso

1313. M. marianum, Inst. Pasteur of Lyon, M. Suzanne

2465, 4333. M. scrofulaceum, University of Montreal, E. H. Prissick and A. M. Masson

227, 27, HI-5887, AC-134. Mycobacterium sp., from different clinical material, UPHG

128, 23, 55, 24, 80, 16. Mycobacterium sp., from cattle with symptoms of respiratory disease, UPHG

8138. M. marinum (Battaglini strain), ATCC 8138

Strains identified as Mycobacterium avium Chester

4109, 4110, 4133, Kirchberg. M. avium, Mayo Clinic, A. G. Karlson. W. H. Feldman

Sheard. M. avium, National Trudeau Bank, W. Steenken jr.

1, 3, 7. Mycobacterium sp., from tuberculous chickens, UPHG

P-17, P-20, P-23, P-25. Mycobacterium sp., from tuberculous chickens, UPHG, G. Kubica

77. Nocardia intracellularis. Communicable Disease Center, Atlanta, L. Ajello.

P-2, P-3, 171, 223, A-225, 248, P-7, 277, 470, 477, 487, 509, 513, 514, 520, 568, 584, 585, 586, 587. Mycobacterium sp., Veterans Administration Hosp., E. H. Runyon, non-photocromogens

SN-405. Mycobacterium sp., Tuberkulose Forschungsinstitut, Börstel, R. Bönicke

AC-2, AC-32, AC-123, AC-271, AC-289. Mycobacterium sp., UPHG, from sputa of people with respiratory disease

SN-418. Mycobacterium suis, Tuberkulose Forschungsinstitut, Börstel, R. Bönicke

Strains identified as Mycobacterium kansasii Hauduroy

P-16, P-18, P-24. Mycobacterium sp., Communicable Disease Center, Atlanta, G. Kubica

P-22, P-1, CAL-265, 266 Ohio, P-16, P-8, 488, 410, 79, 212, 22, 259, 184, 365. Mycobacterium sp., Veterans Administration Hospital, Runyon

SN-501, SN-504, SN-506, SN-510, SN-511. Mycobacterium sp., Tuberkulose Forschungsinstitut, Börstel, R. Bönicke

685-4, C-931, C-457. Mycobacterium sp., strains RW, VM, and VS from Tuberculosis Research Institute of Prague, Czechoslovakia, M. Kubin 
The third branch (III) includes micro-organisms that show a slow rate of growth and a very low capacity to utilize carbohydrates; belonging to this branch are Mycobacterium kansasii (photochromogens), M. avium (non-photochromogens), M. marianum (scotochromogens) and $M$. gordonae sp.nov. (scotochromogens).

A list of the strains studied is shown in Table 1 . They are grouped under the specific epithet that, according to our results, corresponds to each of them. It was possible to classify 187 strains out of a total of 229 studied; while the remaining 42 strains belonged both to the irregular branch (16 strains) and to intermediates between categories (26 strains).

\section{DISCUSSION}

The use of the Adansonian analysis of the physiological properties of mycobacteria permits their separation into twelve different categories. The differences between them depend on the cornbination of various characters.

Some variations can exist in each category between strains or groups of strains, with the consequent formation of subgroups as has been mentioned previously (Bojalil \& Cerbón, 1961). For instance, in the category Mycobacterium fortuitum there are two subgroups, one capable and the other incapable of producing acid from mannitol. However, the high similarity index shown by these two sub-groups makes it impracticable to separate them, and recognition of the subgroups would unnecesarily increase the number of taxa.

The presence of strains intermediate between categories suggests the existence of other strains that could form a continuous metabolic spectrum, that would make difficult the separation of related categories. Thus, some groups now considered as species might constitute, in the future, subcategories or varieties. If, however, the categories are formed only with micro-organisms showing a high similarity index, a useful taxonomic schema can be obtained. In practice, it is not difficult to distinguish several categories that differ only in one or two absolute characters. For instance, Mycobacterium flave'scens sp.nov. shows a metabolism similar to that of $\boldsymbol{M}$. fortuitum, differing only in that the former is pigmented and grows slowly and that the latter is non-pigmented and grows rapidly. Therefore, it is impossible to place a scotochromogen into a group of rapidly growing non-pigmented mycobacteria. Furthermore, a better delimitation of some of these groups could be obtained with the use of other additional tests, such as the presence of amidases (Bönicke, 1960).

An Adansonian classification based on metabolism, clearly shows the relationships between species. Micro-organisms that exhibit a greater metabolic capacity correspond to rapidly growing mycobacteria, while those with a lesser metabolic capacity generally show a slow rate of growth. This fact permits the formation of three metabolic branches: each of them includes species that form natural groups and can be accepted as logically classified. Other natural groups were also observed in each of these three branches and were constituted by unnamed strains. The new categories so formed were named because their characteristics do not correspond to any previously known species.

The designation of neo-types of co-type for known species, of holotypes for those newly described and the general properties of the different categories of the mycobacteria, are noted in Table 2. Branch I is constituted by rapidly growing microorganisms, and includes Mycobacterium smegmatis, and $M$. phlei that have been 


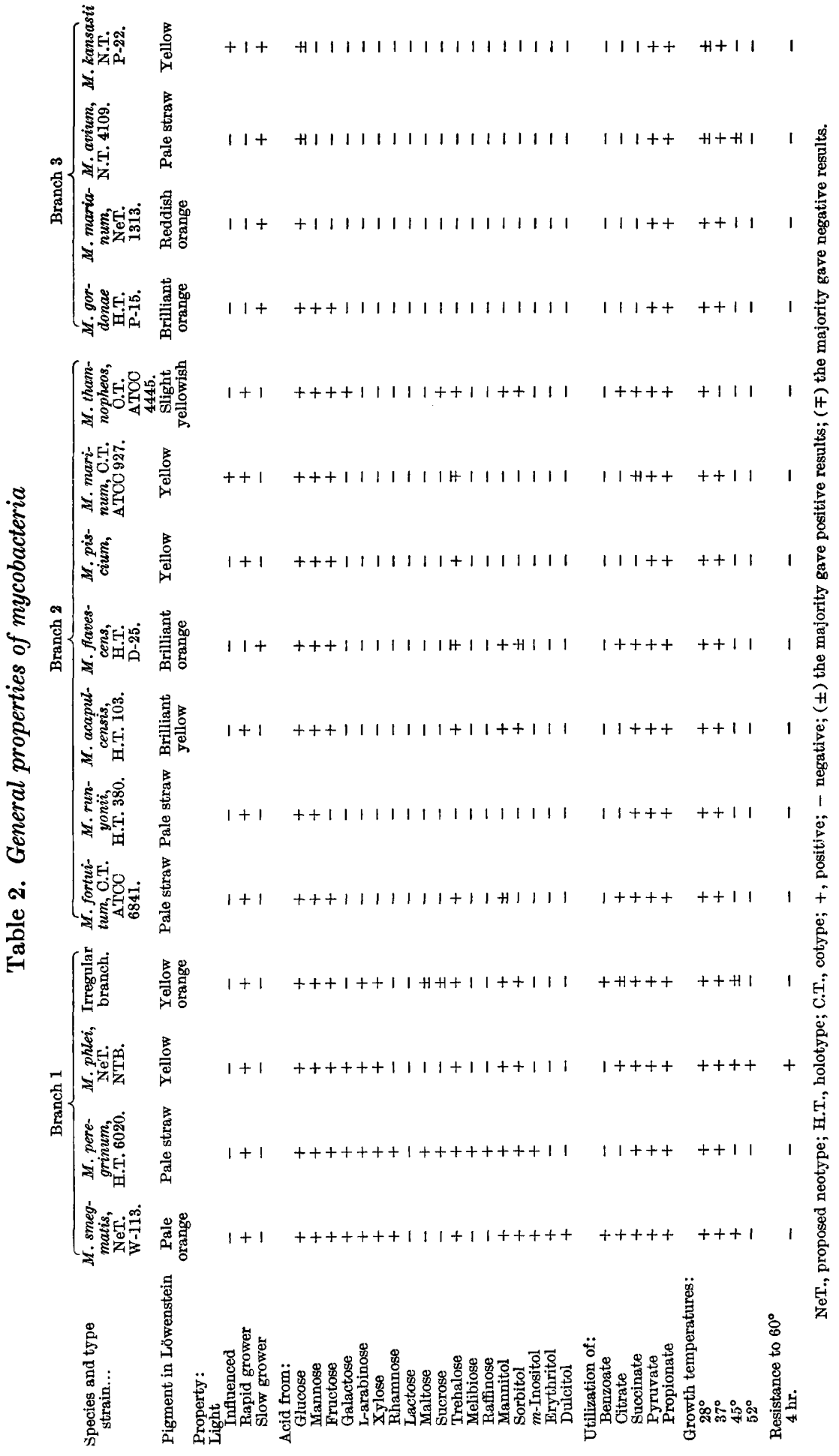


adequately characterized (Gordon \& Smith, 1953; Penso et al. 1951), and a group of other strains that show the greatest metabolic capacity of all the strains studied, being therefore distinct from the other species. For this group, the name of $\boldsymbol{M}$. peregrinum sp.nov. is proposed (Latin adjective, strange, foreign) because they are the only non-pigmented strai is in branch I. The properties of one of these last strains has been previously repored, as strain number $40(6020)$ (Bojalil \& Cerbón, 1961, p. 341).

Besides the species mentioned, there are a number of unnamed micro-organisms (irregular branch) that also show a high metabolic capacity and a rapid rate of growth, and are, therefore, included in this branch. The disparity between the characters of members of this group does not allow their inclusion in any of the aforementioned species, nor do they form new groups.

Branch I can easily be differentiated from the other branches by an absolute distinctive character: the utilization of pentoses (xylose, L-arabinose and rhamnose).

Branch II includes: Mycobacterium fortuitum, $\boldsymbol{M}$. acapulcensis sp.nov. and M. runyonii sp.nov. The last two corresponding to groups 2 and 3 previously described (Cerbón \& Bojalil, 1961). These groups retain their individuality in the present comparative study and a:e therefore named acapulcensis, from Acapulco, a town on the Pacific coast of Mexico, where they were isolated, and runyonii, after R. E. Runyon who established the preliminary subdivision of the atypical mycobacteria.

Other rapidly growing strain; belonging to this branch are Mycobacterium marinum, and $\boldsymbol{M}$. thamnopheos, hut they have an optimal growth temperature of $28^{\circ}$ to $32^{\circ}$. After several transplants, $M$. marinum can grow well at $37^{\circ}$. Also included in branch II are a small group of scotochromogen strains, named $\boldsymbol{M}$. flavescens sp.nov. (I. part. adj. becoming yellow). Although slow growers, they show a greater index of similarity with the species of this branch than to those of branch III, which are formed exclusively by slow-growing micro-organisms.

Strains received as Mycobacteri im balnei (Linell \& Norden, 1954) showed similar properties to M. marinum (Aronson, 1926) as has been already pointed out (McMillen \& Kushner, 1959; Bojalil, 1959). 'Therefore, $M$. balnei was considered as synonymous with $\boldsymbol{M}$. marinum. The physiologival properties described in Table $\mathbf{2}$ for this species are not entirely in accord with those reported by others who showed that they utilize $\mathrm{I}$-arabinose (Gordon, 1937), and that they do not use mannose and fructose (Ross, 1960). The strains here studied did not utilize L-arabinose and they did utilize mannose and fructose.

The strain received as Mycobaterium marinum ATCC 8138 (Battaglini strain) is shown not to belong to this species, because it differs in various characters from the other strains. According to its characteristics it belongs to the species $\boldsymbol{M}$. marianum of branch III.

Mycobacterium piscium (Dubard, 1897; Bergey et al. 1923) and M. thamnopheos, (Aronson, 1929) apparently are two valid species. However, it is necessary to study a large number of strains to define better their properties, since the results obtained differ from other observations (Gurdon, 1937; Ross, 1960).

Some species of branch II utilize trehalose, while others do not use it. Apparently a relationship exists between the utilization of this substrate and the general metabolic capacity, since the micro-organisms that utilize it show a greater ability to use other substrates. 
Branch III is formed by Mycobacterium gordonae sp.nov. (scotochromogen), $\boldsymbol{M}$. marianum (scotochromogen), $\boldsymbol{M}$. avium (non-photochromogen) and $\boldsymbol{M}$. kansasii (photochromogen). All show a low metabolic capacity and grow slowly. This branch could include $\boldsymbol{M}$. ulcerans, $\boldsymbol{M}$. tuberculosis and $\boldsymbol{M}$. bovis since they do not utilize trehalose or most of the other substrates used in this work.

Mycobacterium gordonae sp.nov. (after Miss R. E. Gordon of Rutgers University who has done so much in establishing the classification of mycobacteria) is the species that shows the highest metabolic capacity; it utilizes mannose and fructose, which are not used by other members of this branch. All species utilize glucose, although some strains of $\boldsymbol{M}$. avium, $\boldsymbol{M}$. kansasii and $\boldsymbol{M}$. marianum do not utilize this substrate. The differentiation between the last three species is difficult when it is based only on their utilization of carbohydrates. However, they can be distinguished: $\boldsymbol{M}$. marianum is a scotochromogen, $\boldsymbol{M}$. avium does not produce pigment, at least in young cultures, and $\boldsymbol{M}$. kansasii produces pigment only in the presence of light. The differences between these categories can be made more evident by the use of other tests such as the capacity to metabolize amides. $M$. kansasii decomposes urea but not pyrazinamide, while $\boldsymbol{M}$. avium does not decompose urea but liberates ammonia from pyrazinamide (Bönicke, 1960). However, deamidation tests are not always able by themselves to delimitate the different categories of mycobacteria. An analysis of the results obtained by the use of these tests will be published later.

Non-photochromogen mycobacteria were included under the specific name of Mycobacterium avium, because of the great similarity between them (Bojalil \& Cerbón, 1960). This similarity is based mainly on negative data but other findings seem to confirm it. Bönicke (1960) states that these strains have similar capacities by which they metabolize amides. Palmer, Edwards, Hopwood \& Edwards (1959) and Smith et al. (1961) report that the response of many individuals to different tuberculins from Battey or avian strains is practically the same and Smith et al. (1960) have shown the presence of the same special type of lipid. Other similarities have also been found (Feldman, Davis, Moses \& Adberg, 1943; Engbaek, Friis \& Søeborg-Ohlsen, 1957; Takeya, Zinnake, Yamura \& Toda, 1960).

There is some tendency to separate Mycobacterium avium from the Battey type micro-organisms. One of the most discussed facts has been the degree of virulence for chicken, which is high for $M$. avium but non-photochromogenic strains show little pathogenicity for this animal. This is not an absolute criterion, since nonvirulent strains of $M$. avium exist (Winn \& Petroff, 1933; Branch, 1933; Will, Froman, Krasnow \& Bogen, 1957; Doer, Smith \& Altman, 1959). Other slight differences have been reported in arylsulphatase activity (Kubica \& Beam, 1961), catalase activity (Bojalil \& Cerbón, 1960) and sensitins (Magnusson, Engbaek \& Bentzon, 1961). These differences are of degree only, since there are representative strains of both $\boldsymbol{M}$. avium and the Battey type with identical enzymic activity. It is believed, therefore, that in the absence of sufficient proof that would permit the separation of these micro-organisms, they still must be considered as a single group.

A key for a practical identification of the different categories was designed (Fig. 3); this is based on the most constant characters of each group. However, if a strain is aberrant in some of its properties, it must be classified considering the characters listed in Table 2. 

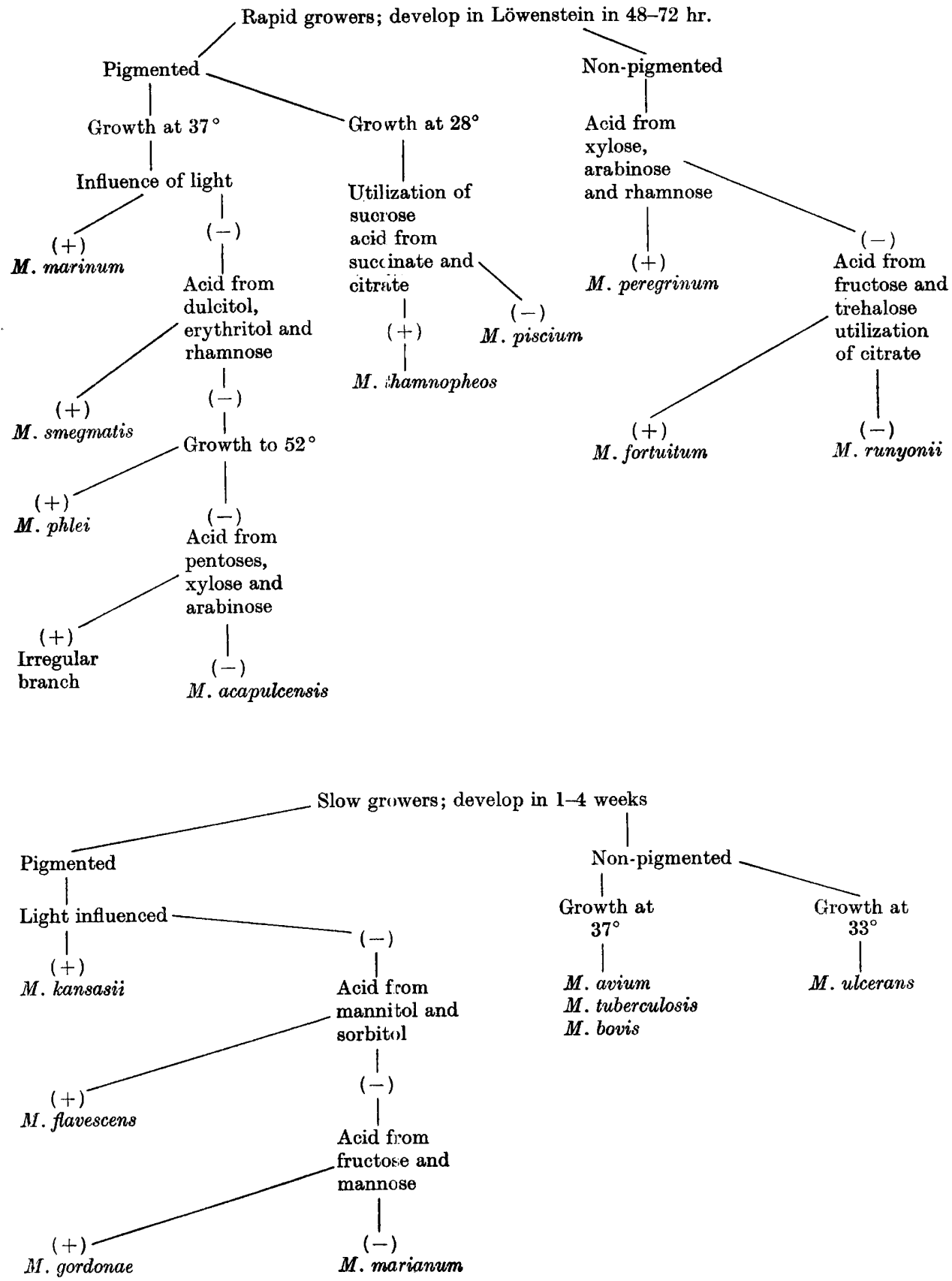

Fig. 2. Simplified scheme for the identification of mycobacteria.

\section{DESCRIFTION OF NEW SPECIES}

Only the most outstanding and distinctive characters will be mentioned, since all the properties studied are noted in Table 2. 
Branch I. Mycobacterium peregrinum sp.nov. (L. adj. peregrinus, strange, foreign).

Rapid growing, acid-fast bacilli, with visible growth in 24-48 hr. in most ordinary culture media.

Löwenstein-Jensen: abundant, confluent, smooth, buff or pale straw-coloured growth.

Temperature relations: optimum for growth, $37^{\circ}$; grows at $28^{\circ}$ but not at $45^{\circ}$; does not survive $4 \mathrm{hr}$. at $60^{\circ}$.

Glycerol agar slants; good growth.

Acid from glucose, mannose, fructose, galactose, L-arabinose, xylose, rhamnose, maltose, sucrose, trehalose, melibiose, raffinose, mannitol, sorbitol, $m$-inositol. No acid from lactose, erythritol or dulcitol.

Utilizes succinate, pyruvate and propionate but not benzoate or citrate.

Proposed holotype: strain 6020 (Unidad de Patología, Hospital General, México).

Distinctive characters. This species may be distinguished from closely related species such as Mycobacterium smegmatis by its ability to produce acid from maltose, sucrose, melibiose and raffinose. It is non-pigmented and does not utilize benzoate or citrate and does not produce acid from erythritol or dulcitol.

Source: one strain was isolated from bronchial aspiration of a child with respiratory symptoms and another from nasal exudate of a cow.

Branch II. Mycobacterium acapulcensis sp.nov. (From Acapulco, a town on the Pacific coast of México.)

Rapid growing acid-fast bacilli, with visible growth in $24-48 \mathrm{hr}$. in most ordinary laboratory media.

Löwenstein-Jensen: abundant, wrinkled, waxy, intense yellow colonies.

Glycerol agar slants: spreading growth, dry with slightly discoloured yellow pigment.

Temperature relations: grows well from $28^{\circ}$ to $37^{\circ}$; optimal temperature $37^{\circ}$; does not grow at $45^{\circ}$ and does not survive $4 \mathrm{hr}$. at $60^{\circ}$.

Acid from glucose, mannose, fructose, trehalose, mannitol, and sorbitol, but not from galactose, L-arabinose, xylose, rhamnose, lactose, maltose, sucrose, melibiose, raffinose, $m$-inositol, erythritol and dulcitol.

Utilizes succinate, pyruvate and propionate but not benzoate or citrate.

Proposed holotype: strain AC-103 (Unidad de Patología, Hospital General, México).

Distinctive characters: these strains are distinguished from Mycobacterium thamnopheos, a closely related species in that they do not produce acid from galactose or sucrose, or utilize citrate, and they grow at $37^{\circ}$.

Source: isolated from sputum of people with pulmonary diseases, usually tuberculosis.

Mycobacterium runyonii sp.nov. (After E. H. Runyon, The Veterans Administration Hospital, Salt Lake City.)

Rapid growing acid-fast bacilli, that grow in most ordinary culture media in 24-48 hr.

Löwenstein-Jensen: good growth, smooth, confluent, soft consistency, nonpigmented.

Glycerol-agar-slants: good growth. 
Temperature relations: optimal for growth $37^{\circ}$; grows at $28^{\circ}$ but not at $45^{\circ}$; does not survive $4 \mathrm{hr}$. at $60^{\circ}$

Acid from: glucose and mannose only.

Utilizes succinate, pyruvate and propionate, but not benzoate or citrate.

Proposed holotype: strain number 380 (E. H. Runyon, Vet. Admin. Hosp., Salt Lake City).

Distinctive characters: non-pigmented, rapidly growing micro-organisms with cultural properties similar to those of Mycobacterium fortuitum, from which they differ in that they are unable to produce acid from fructose, trehalose, mannitol and do not utilize citrate.

Source: isolated from sputum (in absence of tubercle bacilli) from people with pulmonary lesions.

Mycobacterium flavescens sp.nov. (L. v., flavesco, to become golden yellow).

Slowly growing acid-fast bacilli, that does not grow well in ordinary culture media.

Löwenstein-Jensen: the development is detected after one or more weeks; colonies are of soft consistency, butyrous, adherent, difficult to remove and of intense orange colour (scotochromogen).

Glycerol agar slants: scarce development, orange pigment at $37^{\circ}$, does not grow at $28^{\circ}$.

Temperature relations : optimal growth at $37^{\circ}$, scanty growth at $28^{\circ}$ in LöwensteinJensen; does not grow at $45^{\circ}$ or survive $4 \mathrm{hr}$. at $60^{\circ}$.

Acid from: glucose, mannose and fructose; some strains produce acid from trehalose, sorbitol and mannitol.

Utilizes citrate, succinate, pyruvate and propionate but not benzoate.

Proposed holotype: strain number D-25 (Unidad de Patología, Hospital General, México).

Distinctive characters: these strains are closely related to Mycobacterium fortuitum from which they can be distinguished by their intense pigment production, their slow rate of growth and their inability to grow well in glycerol agar both at $28^{\circ}$ and $37^{\circ}$.

Source: isolated from guinea-pigs with tuberculosis arrested by chemotherapy and from autopsy material.

Branch III. Mycobacterium gordonae sp.nov. (After Miss Ruth E. Gordon of Rutgers University.)

Slowly growing acid-fast bacilli that do not grow in ordinary culture media. Development is detected only after 9-12 days.

Löwenstein-Jensen: abundant, soft consistency, orange coloured, adherent growth (scotochromogen).

Glycerol agar slants: scarce growth at $37^{\circ}$, orange coloured and generally no growth at $28^{\circ}$.

Temperature relations: optimal growth $37^{\circ}$, scanty at $28^{\circ}$ in Löwenstein; does not grow at 45 or survive $4 \mathrm{hr}$. at $60^{\circ}$.

Acid from: glucose mannose and fructose only.

Utilizes pyruvate and propionate but not benzoate, citrate or succinate.

Proposed holotype: strain number P-15 (E. H. Runyon, Vet. Admin. Hosp., Salt Lake City). 
Distinctive characters: their capacity to produce acid from mannose and fructose makes possible their differentiation from its most related scotochromogen species, Mycobacterium marianum.

Source: isolated from human pathological material.

The authors wish to thank all research workers who kindly provided strains for study. To Dr P. H. A. Sneath (National Institute for Medical Research, London, for correction of the typescript and valuable suggestions, and $\mathrm{Dr} \mathbf{H}$. Brandt (Unidad de Patología, Hospital General, México) for help in the preparation of the manuscript.

\section{REFERENCES}

Aronson, J. D. (1926). Spontaneous tuberculosis in salt water fish. J. infect. Dis. 39, 315.

Aronson, J. D. (1929). Spontaneous tuberculosis in snakes. N.sp. Mycobacterium thamnopheos. J. infect. Dis. 44, 215.

Bergey, D. H., Harrison, F. C., Bried, R. S., Hammer, B. W. \& Huntoon, F. M. (1923). Bergey's Manual of Determinative Bacteriology. 1st ed., p. 377. Baltimore: Williams \& Wilkins Co.

BojaliL, L. F. (1959). Estudio comparativo entre Mycobacterium marinum y Mycobacterium balnei. Rev. lat.-amer. Microbiol. 2, 169.

Bojalil, L. F. \& CERbón, J. (1960). A comparative study of non-photochromogenic mycobacteria and Mycobacterium avium. Amer. Rev. resp. Dis. 81, 382.

Bojalil, L. F. \& Cerbón, J. (1961). Taxonomic analysis of non-pigmented, rapidly growing mycobacteria. J. Bact. 81, 338.

Bönicke, R. (1960). 'The classification of atypical mycobacteria by their power to metabolize amides. Germ. med. Monthly, 5, 232.

Branch, A. (1933). A study of acid-fast organisms other than mammalian tubercle bacilli isolated from disease in man. Tubercle, 14, 337.

Cerbón, J. \& Bojalil, L. F. (1961). Physiological relationships of rapidly growing mycobacteria. J. gen. Microbiol. 25, $\%$.

Durr, F. E., Surtir, D. W. \& Altman, D. P. (1959). A comparison of the virulence of various known and atypical mycobacteria for chickens, guinea pigs, hamsters, and mice. Amer. Rev. resp. Dis. 80, 876.

Engbaek, H. C., Frirs, 'T. \& Søeborg Ohlsen, A. (1957). A case of lung disease caused by an atypical acid-fast organism. Acta tuberc. scand. 34, 1945.

Feldman, W. H., Davis, R., Moses, H. E. \& Adberg, W. (1943). An unusual Mycobacterium. Isolated from sputum of a man suffering from pulmonary disease of long duration. Amer. Rev. tuberc. 48, 82.

Gordon, R. E. (1937). The classification of acid-fast bacteria. J. Bact. 34, 617.

Gondon, R. E. \& Smith, M. M. (1953). Rapidly growing, acid fast bacteria. I. Species descriptions of Mycobacterium phlei Lehmann \& Neumann and Mycobacterium smegmatis ('Trevisan) Lehmann \& Neumann. J. Bact. 66, 41.

Hit., L. R. (1959). The Adansonian classification of the staphylococci. J. gen. Microbiol. $20,277$.

Kubica, G. P. \& Beam, R. E. (1961). The arylsulfatase activity of acid-fast bacilli. II. The differentiation of Mycobacterium avium from the unclassified group III nonphotochromogenic mycobacteria. Amer. Rev. resp. Dis. 83, 733.

Lrnelt, F. \& Norden, A. (1954). A new acid-fast bacillus occurring in swimming pools and capable of producing skin lesions in humans. Acta tuberc. scand. sup. 33, 84.

Magnusson, M., Engbaek, H. C. \& Bentzon, M. W. (1961). Specificity of mycobacterial sensitins. II. Studies in guinea pigs with purified sensitin prepared from unclassified acid-fast bacilli. Amer. Rev. resp. Dis. 83, 69.

MCMillen, S. \& Kushner, D. S. (1959). Mycobacterium marinum Aronson (1926). Bact. Proc. p. 31. 
Palmer, C. E., Enwards, L. B., Hopwood, L. \& Edwards, P. Q. (1959). Experimental and epidemiological basis for ir terpretation of tuberculin sensitivity. J. Pediat. 55, 413.

Penso, G., Ortali, V., Gaudiano, A., Princivalle, M., Vella, L. \& Zampieri, A. (1951). Studi e ricerche sui micobatte i. VII. II. Mycobacterium phlei (Lehmann e Neumann, 1899, pro. part). R.C. Ist. sup. Sanit. 14, 855.

Ross, J. A. (1960). Mycobacteritm salmoniphilum Sp.nov. from salmonoid fishes. Amer. Rev. resp. Dis. 81, 241.

Runyon, E. H. (1955). Coopera ive study of mycobacteria. Amer. Rev. Tuberc. 72, 866.

Singer, J. \& Cysner, E. (1952). Urease activity in mycobacteriaceae. Amer. Rev. Tuberc. 65, 779.

Smith, D. T., Johnston, W. W. CaIn, I. M. \& Schumacher, M. (1961). Changes in the tuberculin pattern in students between 1930 and 1960. Amer. Rev. resp. Dis. 83, 213.

Smith, D. W., Randali, H. M., Maclennan, A. P., Putney, R. K. \& Rao, S. V. (1960). Detection of specific lipids in nycobacteria by infrared spectroscopy. $J$. Bact. 79, 217.

SNeath, P. H. A. (1957). 'The af plication of computers to taxonomy. J. gen. Microbiol. $17,201$.

Sneath, P. H. A. \& Cowan, S. T. (1958). An electro-taxonomic survey of bacteria. J. gen. Microbiol. 19, 551.

'TakeYa, K., Zinnake, Y., Yamt RA, K. \& Toda, 'T. (1960). Bacteriophage susceptibility and tuberculin specificity of unclassified mycobacteria. Amer. Rev. resp. Dis. 81, 674 .

Wmescer, M. V. (1951). A sintple procedure for the preparation of egg medium for Mycobacterium tuberculosis. J. Bact. 62, 244.

Will, D. W., Froman, S., Krass ow, I. \& Bogen, E. (1957). Cultural characteristics and drug bacteriophage resistance of avian tubercle bacilli. Amer. Rev. Tuberc. 76, 43.5.

Winn, W. A. \& Petrofe, S. A. (1933). II. A new conception of the pathology of experimental avian tuberculosis with special reference to the diseases produced by dissociated variants. J. exp. Med. 57, 239 